\title{
Comparing distance education and conventional education: observations from a comparative study of post-registration nurses
}

\author{
Tim Duffy, lain Gilbert,* David Kennedy* and Poon Wai Kwong** \\ *University of Paisley ** Online Education, Hong Kong \\ email: david.kennedy@paisley.ac.uk
}

\begin{abstract}
This retrospective study presents a comparison of assessment results achieved by distancelearning students and classroom-based students undertaking the same module in a degree course. The purpose of the comparison is to provide some objective measurement of the quality of distance education in relation to conventional classroom-based education. The authors have selected three groups of students, who have all undertaken the same module in the B.Sc. Health Studies degree programme offered by the University of Paisley. One group (in Paisley) undertook their studies by means of conventional classroom-based education, the second (in Hong Kong) by supported distance learning with face-to-face contact in the form of tutorials, and the third (in a geographically dispersed group in the United Kingdom and other countries) by supported distance learning with no face-to-face contact. The results obtained by these three groups of students were analysed. Because of the differences in the size of the groups, the Kruskal-Wallis 1-Way Anova test was applied to validate the face value findings. The authors include findings from the literature comparing distance education with conventional education and from cross-cultural studies to present their data in context. Analysis of the assessment results showed that students from all three groups were successful in their studies, but the students studying by distance learning obtained significantly higher end-of-module results than their classroom-based colleagues. This latter finding reflects the conclusion that other investigators have reached. In their discussion the authors identify educational, cultural and personal factors that may help to explain their findings. A limitation in the study is that it concerns only one module in the degree programme. The research now moves on to comparing students who have undertaken the whole degree programme by the means described.
\end{abstract}

\section{Introduction}

In the United Kingdom, the university with the highest number of students is a distance education university (HESA, 2000). The higher education sector can clearly deliver 
distance education. However, in the current ideological and financial drive towards increasing the distance education component of higher education, one of the key questions is this: is the quality of the distance education offered in higher education equivalent to the quality of its classroom-based education?

This paper reports a study carried out in the University of Paisley, which attempts to shed some light on this question. It makes a specific comparison of the results achieved by classroom-based students and distance-learning students undertaking the same degree course. All the students under comparison study the same module material and undertake identical assessments. But they study in different modes and in different locations in the world: some based on the campus in the town of Paisley and undertaking the course by conventional classroom-based learning; others geographically dispersed - with the majority living in Hong Kong - and accessing the course by distance learning.

One indicator of the quality of learning and teaching is the results that students achieve in assessable coursework. Accordingly we have phrased our research question in the following terms: do post-registration nurses studying by distance learning achieve the same assessment results as colleagues undertaking the same module by conventional classroom-based study?

\section{Comparing distance education and classroom education}

Peterson (2001) states that scholars of distance learning fall into two main camps. The first camp argues that distance learning is an opportunity for those that could not usually attend university to participate in tertiary education; that it promotes lifelong learning; and that 'the experience of an online course can be as rich and fulfilling as the experience of a traditional course'. They argue that more diverse populations of students with different learning styles can benefit from online courses.

The second camp argues that in distance learning the focus is on teaching rather than on learning, and that the claims of flexibility are not reflected in present distance learning courses. They argue that students are frustrated, not just by the feelings of isolation but by lack of feedback from their teachers and difficulty in understanding written instructions given to them (Peterson, 2001). Ng (2001) highlights a number of issues relating to problems of delivering distance learning. He noted that social cohesion with the group of students was not good and that communication between students was limited and focused mainly on personal rather than academic issues. Several students in his study felt anxiety about using electronic (email) communication.

Edwards, Hugo, Cragg and Peterson (1999) assert that 'research generally shows no significant difference in educational outcomes [that is, course achievement and satisfaction with instruction] between courses taught through distance education and those offered in the regular classroom'. Such a conclusion is a typical one from the research looking at differences in educational outcomes associated with conventional classroom-based education and distance education. The issue of 'significant difference' is one that Russell (1999 and 2002) and McGreal (2002) have both tackled by assembling annotated bibliographies of comparative research studies.

The authors of this present study have carried out a meta-analysis of thirty-seven studies that specifically deal with online education and which are reported in either Russell's No 
Significant Difference or McGreal's Significant Difference annotated bibliographies. The meta-analysis is restricted to research reported in the decade 1992-2002. The findings from this meta-analysis are presented in Table 1. This meta-analysis shows that most studies have focused on academic performance as their means of comparing the effectiveness of online distance education with conventional classroom-based education. The majority (16 studies out of 31) have found that there is no significant difference in the academic performance of online students when compared with on-campus students. However, a significant number of studies (13 out of 31 ) find that students in online courses outperform conventional students in terms of academic performance measured by examinations. A majority of studies found that the quality of learning and the participation in learning is also higher in distance education.

In the area of student satisfaction, the picture is reversed. A significant number of studies (four out of seven) report that the on-campus students are more satisfied with their courses than the online students.

\begin{tabular}{ccccc}
\hline Focus of the research reported & $\begin{array}{c}\text { Number of } \\
\text { studies }\end{array}$ & $\begin{array}{c}\text { Number of } \\
\text { studies } \\
\text { reporting no } \\
\text { significant } \\
\text { difference }\end{array}$ & $\begin{array}{c}\text { Number of } \\
\text { studies finding } \\
\text { in favour of } \\
\text { online } \\
\text { education }\end{array}$ & $\begin{array}{c}\text { Number of } \\
\text { studies finding } \\
\text { in favour of } \\
\text { conventional } \\
\text { education }\end{array}$ \\
\hline
\end{tabular}

Academic performance

measured by examinations, tests

or grades

Student satisfaction with

the course

Quality of learning and learning

outcomes achieved

Student participation in

the course

Retention rates

Pass rates

Faculty evaluation of the course

\begin{tabular}{llll}
31 & 16 & 13 & 2 \\
7 & 3 & 0 & 4 \\
5 & 2 & 3 & 0 \\
2 & 0 & 2 & 0 \\
2 & 0 & 1 & 1 \\
2 & 0 & 1 & 1 \\
2 & 1 & 1 & 0 \\
\hline
\end{tabular}

Table 1: Meta-analysis of research studies reported in the 'No Significant Difference' and 'Significant Difference' annotated bibliographies

We might, then, summarize a decade of literature comparing the effectiveness of classroom-based education and distance education in the following terms: distance education involving online support is at least as effective as classroom-based education in terms of academic performance measured by examination, and in several cases more effective. It seems to promote a higher level of student participation. But it does not obtain such high student satisfaction ratings as classroom-based education.

This summary needs to be qualified. In 1999, Phipps and Merisotis conducted a review of the contemporary literature on the effectiveness of distance learning for the American Institute of Higher Education Policy (IHEP). Their overall conclusion agrees with the meta-analysis presented above, although they report more positive studies on student 
satisfaction. But they add a caveat: 'The most important problem is that the overall quality of the original research is questionable and thereby renders many of the findings inconclusive' (Phipps and Merisotis, 1999: 18). One of the limitations of the research that they identify, for example, is that many of the studies focus on part of a course, rather than a whole educational programme. That is a charge that the authors of this paper recognize may be laid against their own study.

\section{Educational culture in Hong Kong and Scotland}

It is appropriate to set the study reported in this paper in its educational and cultural context. There are two main educational backgrounds to be aware of: the British (that is, the distinct Scottish and English) educational backgrounds of the on-campus students and of the distance-learning students who are supported directly from the university with no face-to-face teacher contact; and the Chinese educational background of the distance learning students who live in Hong Kong and who have some face-to-face contact with their teachers.

Because of its colonial history, the educational culture in Hong Kong is derived from two distinct traditions, Chinese and English. The Chinese tradition holds a 'deep reverence for learning, a predilection for the integration of knowledge and delight in formal reasoning' (University Grants Committee, 1996). The English tradition is concerned with a far more pragmatic approach to learning. Both systems have moved away from elitist traditions toward more inclusive, mass higher education systems.

Li-Yixian (1992) observes that most students in Hong Kong study solely for the purpose of obtaining a degree and, consequently, to improve their chances in the labour market. This aligns with the assertion made by Sumner (2000) that distance education is frequently 'instrumental' and 'serves the system'.

The Scottish dimension of the degree programme probably spans both the English and the Chinese philosophies. In the Report of the Scottish Committee to the National Inquiry into Higher Education, Garrick detected a 'strong belief in Scotland in the value of education, partly for its own sake and partly to overcome economic or social disadvantage' (Garrick, 1997).

\section{Background to the study}

The University of Paisley first offered its B.Sc. in Health Studies in 1991. This course was specifically designed to meet the demand from health care personnel with a desire to upgrade their professional qualifications to degree status. It aimed to do this by offering a flexible, part-time mode of study while offering credit for prior accredited learning. To date more than one thousand students have graduated through the conventional on-campus delivery programme. These students have been health professionals, mostly nurses, working in the West and Central Belt of Scotland.

In 1995 further flexibility was built into the delivery when this programme was also made available by computer-supported distance learning. At the time of writing (January 2002), over 800 students have graduated through the distance-learning programme. Those 
students have been health professionals, mostly nurses, and the bulk of them are working in Hong Kong. With the advent of the new Hong Kong Hospital Authority in 1992, the bachelor's degree became the preferred route for a Registered Nurse to advance to the status of Nursing Officer. Large numbers began to seek opportunities to further their studies. The majority of them preferred distance learning, from either Australian or United Kingdom universities. Paisley University was the only UK university with a presence in Hong Kong that offered a degree in Health Studies.

The main overall distinction we draw in this paper is between the conventional classroombased delivery and the distance-learning delivery. However, within the distance-learning delivery, there are two main variations in the support given to students. One version incorporates some face-to-face support from an on-site tutor. This is the pattern of delivery for our students in Hong Kong. The other version involves no face-to-face contact but relies solely on computer-mediated support by teachers based in the university. This is the pattern of delivery for our students who are dispersed throughout the United Kingdom or situated in Norway or Switzerland.

In summary, the three forms of course delivery are:

1. on-campus delivery, in conventional classroom-based format;

2. supported distance learning using networked learning, with optional face-to-face contact;

3. supported distance learning using networked learning, with no face-to-face contact.

This paper focuses on one module within the B.Sc. Health Studies programme 'Professional Practice and Teaching'. This is a module that enables health professionals to study, and apply in practice, educational principles which are applicable in their clinical practice when teaching patients or junior colleagues. We have selected this module because all the students in the groups that we will consider have undertaken the same generic assignment. We can use the mean scores achieved by each group as an outcome measure to make reliable comparisons between the groups.

\section{The different forms of course delivery}

This section gives an outline of the three modes of delivery of the module 'Professional Practice and Teaching' with a particular focus on the following aspects:

- the actual mode of delivery;

- the processes of student support; and

- the assessments which the students undertake.

\section{Mode of delivery}

The conventional on-campus delivery of the module is taught over a period of twelve weeks (one semester). The class meets for two hours one evening per week. The main approach to teaching the module is the modified lecture. Within the lecture there are exercises focused on the development of specific teaching skills.

The distance-learning students receive core material in the form of printed booklets. They also receive that same material as an electronic document, in hypertext format. It is 
important to note that the course content for the distance-learning students is identical to the course content for the classroom-based students. The distance-learning version of the course is a development of the lecture-based version, and is not an alternative course. The distancelearning material incorporates interactive features, exercises and self-assessment questions.

\section{Student support}

Support for the on-campus students

Within the timetable for the conventional on-campus delivery there are embedded two classes, which are entitled 'tutorial support'. These classes occur the week before the assignments are due. In all, four hours in the module are designated for student support. Ongoing tutorial support was usually given immediately after the taught classes, lasting anything up to an hour. The learners were informed of the availability of individual tutorial support during the day, but this service is seldom used. Occasionally telephone tutorial support was requested and given.

\section{Support for all distance-learning students}

Within the distance-learning approach there are two different modes for supporting the student, one in which there is face-to-face contact, and one without. In both modes, communication between the students and the teacher and between the students and each other is maintained by an 'electronic campus'. This is a virtual learning environment that supports email, asynchronous (delayed time) and synchronous (real-time) discussion and a repository of relevant documents and articles. Students have access to their tutor throughout the module, and should have an answer within twenty-four hours of making an enquiry.

\section{Support for distance-learning students who have only online contact}

In the no-face-to-face contact mode, as exemplified by the United Kingdom mode of delivery, the support the students received - and gave to each other - was carried out online. Email correspondence between the teacher and the students during the module consisted of both general messages addressed to the whole student group and individual messages for individual students.

The teacher initiated 24 general messages in the eight weeks of the module. These messages communicated information that all the students required. The number of messages sent by the teacher to individual students ranged from 14 to 24 messages. These messages concerned specific issues about which the students wished to consult their teacher. The average number of exchanges was 43 exchanges, or 86 separate messages over the eight weeks of the module (each exchange involves a communication and a response).

Students and the teacher participated in five discussion forums and six teleconferences. In the forums, key topics related to the module and requiring in-depth exploration were discussed online. Participants were free to contribute to this discussion at any time within the week and participation was voluntary. At the end of the week, the discussion was summarized by the teacher and the summary archived as an educational resource. In the teleconferences, which are real-time discussion events, a topic was agreed in advance and participants shared their views by keyboard conferencing.

The major difference between the Hong Kong and the United Kingdom-based distance learning groups was the greater use of electronically mediated discussion by the United Kingdom students. 
Support for distance-learning students who have online contact plus additional face-to-face contact

Distance-learning students in Hong Kong had the benefit of face-to-face contact in the form of tutorials. Attendance at these was variable. These students also used email to send questions or messages once they had identified an issue. This obviated the need to wait until the next available face-to-face tutorial. On average, the teacher received ten emails per week. Messages typically concerned administrative information such as the dates for course commencement and assignment release, as well as information on the scheduling of face-to-face tutorials, topics for discussion and any preparation that was necessary for participation in these.

As most of the students were nurses working shifts, it was often difficult to arrange suitable times to be online together. An attempt was made to arrange teleconferences for the students, but only three students responded online. Forum discussions are not dependent on synchronicity, but the Hong Kong students were noted to be reluctant to respond to the question set for the forum. $\mathrm{Ng}$ (2001) similarly found Hong Kong students to lack social cohesion as a group, to demonstrate limited communication with each other and to show anxiety about computer-mediated communication. There was also a tendency for the students to demand answers from the teacher rather than engage in discussion, the 'instrumental' approach that we have alluded to already from Sumner's (2000) study.

\section{Assessments}

The assignments used in the assessment process were identical for all students taking this module. The assignments involve the students in carrying out a learning needs assessment in their places of work and, on the basis of their analysis of learning needs, delivering an appropriate lesson. They must also evaluate the lesson that they have delivered.

Students made use of different support mechanisms in preparing to submit their assignments. In the distance-learning mode that included face-to-face support, students participated in tutorials allowing them to raise questions and receive guidance. Emails to the teachers increased in frequency in the run-up to the submission date. Some students preferred to page the teacher, allowing them to talk directly with the teacher on the phone and receive an immediate answer to their enquiries.

In the distance-learning mode that excluded face-to-face contact, discussion forums were suspended in the period when assignments were due. Teleconferences continued, as they are a good means by which students can access teachers for last-minute guidance. Some students were entirely independent in the preparation and submission of their assignments. Others made full use of the tutor, by submitting one-page drafts of their ideas for comment, or sections of their proposed assignments for comment. Although these means of support are different in the forms of communication they employ, they are equivalent in effect.

\section{Analysis of the outcomes from assessments}

This study seeks to identify what difference, if any, exists between student performance, as measured by the marks awarded to students from their assignments, and the different delivery modes that have been described. 


\section{Method}

Earlier in this paper we identified three different modes of delivery of this course. For the purposes of this analysis, four student groups are identified and their marks presented. The reason for this increase of groups from three to four for analysis is that one of the groups (the Hong Kong distance-learning student group) comprises two types of student: indigenous Chinese students and expatriate British students. Treating the marks gained by these students separately may enable us to elucidate the influence of culture.

The four groups identified for the purpose of comparison are:

1. Chinese students in Hong Kong studying by distance learning and supported from Hong Kong (group 1, $\mathrm{n}=85$ );

2. British students in Hong Kong studying by distance learning and supported from Hong Kong (group 2, $\mathrm{n}=15$ );

3. British students in the United Kingdom studying by distance learning and supported from Paisley (group 3, $n=17$ );

4. British students studying in a classroom-based environment and supported on campus at Paisley (group 4, $\mathrm{n}=37$ ).

\section{Results}

During the module, students submit two pieces of coursework for assessment - a learning needs assessment that they have carried out and an account and evaluation of a teaching

\begin{tabular}{lcc}
\hline Group & Number & Mean score \\
\hline Group 1 (Chinese, distance learning, Hong Kong) & 85 & 61 \\
Group 2 (British, distance learning, HK) & 15 & 74 \\
Group 3 (British, distance learning, UK) & 17 & 72 \\
Group 4 (British, classroom-based, UK) & 37 & 61 \\
\hline
\end{tabular}

Table 2: Assessment results for the four groups of students: mean scores for the module 'Professional Practice and Teaching'

session that they have conducted. For each of these groups, the average mark for the two pieces of assessed coursework was calculated. The comparison of the mean scores achieved by each of these groups is presented in Table 2 :

It is clear, from the scores presented in Table 2, that these students are successfully meeting the demands of the assessments in this module. The pass mark is 40 per cent and the mean score for each group is well in excess of that. At face value, the scores presented in Table 2 indicate that British students studying by distance learning, either in Hong Kong (group 2) or in the UK (group 3), are achieving the highest scores in this module. Their average scores are almost the same. British students studying on campus (group 4) and Chinese students studying by distance learning in Hong Kong and supported from Hong Kong (group 1) have achieved identical scores in this module. 
Because of the disparate sizes of the groups from which we have derived these mean scores, we then subjected our data to analysis using the Kruskal-Wallis test. When all four groups were considered together, this test confirmed the statistical significance of the difference across group means $(H=45.4163$; significance, $p<.01)$. The differences between the pairs

\begin{tabular}{lc}
\hline $\begin{array}{l}\text { Groups } \\
\text { Compared }\end{array}$ & $\begin{array}{c}\text { H-value from } \\
\text { Kruskal-Wallis }\end{array}$ \\
\hline 1 and 2 & $26.6573^{*}$ \\
$I$ and 3 & $19.1488^{*}$ \\
$I$ and 4 & 0.3869 \\
2 and 3 & 0.6012 \\
2 and 4 & $24.2715^{*}$ \\
3 and 4 & $18.7099^{*}$ \\
\hline
\end{tabular}

Table 3: Comparisons of the mean scores achieved by the four groups of students, using Kruskal-Wallis. ${ }^{*} p<.01$

of groups were then analysed. Application of the Kruskal-Wallis test allowed us to distinguish those face value comparisons between groups which can be substantiated statistically from those which cannot. These comparisons are presented in Table 3 . From the analysis presented in Table 3, we can state the significant findings as follows:

- British students studying by distance learning in Hong Kong achieved a significantly higher average mark than their Chinese counterparts.

- British students studying by distance learning in the United Kingdom achieved a significantly higher average mark than Chinese students studying by distance learning in Hong Kong.

- British distance-learning students, whether based in Hong Kong or in the United Kingdom, achieved a significantly higher average mark than British classroom-based students.

\section{Discussion}

It is important to avoid simplistic cause and effect conclusions about these findings. There are several factors to consider, and we outline these here.

\section{The language of instruction}

The language of instruction for this degree programme is English. This is the first language of the British students in each of the modes of delivery of this course. It is, however, a second language for the Chinese students. For most of them their first language is Cantonese or Mandarin. So, in our comparison of results, we have to bear in mind that our Chinese students are studying the module material and constructing their assignments in a foreign language, while the British students are studying in their mother tongue.

However, we cannot jump to conclusions about the effect of studying in a language that is not the student's first language. Some of the Hong Kong students completed their basic nursing training in Hong Kong Government Schools of Nursing where the language of instruction was English. Moreover, the Hong Kong-based students have to possess an equivalent level of competence in English as the on-campus students in the United Kingdom. Their competence in English is further attested by the internal moderators of their assessable coursework and by the external examiners. 


\section{Cultural differences between Hong Kong and the United Kingdom}

The pattern of social interaction in a society - and particularly the interaction between students and teachers - is an aspect of culture that impinges on the educational experience. We have already noted that Hong Kong students were reluctant to raise questions and to engage in discussion in the public domain of the online forum. Ip, Lee, Lee, Chou, Wootton and Chang (2000) have detected a negative disposition towards critical thinking among Chinese undergraduate nursing students. However, this reluctance is not unique to the Chinese students. The United Kingdom-based students also showed reluctance at times to participate in online discussions. This reticence is, in fact, a widespread and common aspect of online education.

There is, perhaps, among the Chinese students a greater respect for the status and knowledge of the teacher. However, our discussions with other teachers in Hong Kong indicate that this is fading fast. Moreover, Fung and Carr (2000) found that the image of the Hong Kong students as passive and tutor-directed is not borne out. Hong Kong students are rapidly becoming the same as students in the United Kingdom and USA in terms of treating their teachers as sources of information who are open to challenge. This approach was evident in the response of the Chinese students to their teachers when they required help with preparing assignments. The Chinese students made heavy demands on their teachers as the date of submission approached, contacting their teachers by phone, pager and email. This matches exactly the pattern of communication that occurs on campus when the submission of an assignment draws near.

\section{The role of personal ambition and drive}

The prospect of promotion by means of obtaining a degree is a strong motivator for the Chinese students in Hong Kong. Our discussions with the students and their tutors in Hong Kong make it clear that that is their major rationale for undertaking the degree. The appeal of a British degree is also a significant factor in their choice of programme.

However, the British students in Hong Kong are working within the same health care system. They benefit in the same way as their Chinese counterparts from the possession of a relevant degree. Their motivation is likely to be the same. But their marks are significantly higher. Something more than personal ambition and drive lies behind the differences in results that we have found.

\section{Different values placed on higher education}

There is a contradiction in what we have found in terms of the different values placed on higher education in Britain and Hong Kong. On the one hand, we have reported the traditional Chinese reverence for learning, compared with the pragmatic British attitude to learning. On the other hand, we have identified that our Chinese students are more likely to be motivated by the pragmatic prospects of promotion and enhanced salary than our British students.

In fact there is probably a levelling factor to consider - the influence of the profession in which these students are working. It is mandatory for nurses in the United Kingdom to keep their knowledge up to date and to provide evidence of this. In Hong Kong, such updating is not mandatory, but most large Hong Kong hospitals require their nursing personnel to study for Continuing Nursing Education (CNE) points and to achieve a 
minimum number of CNE points each year. It is likely that these mechanisms to ensure continuing professional education override the different values placed on higher education by the two cultural groups that we are considering.

\section{Variations in mode of delivery}

There is a significant difference in the results obtained by students undertaking this module in its different modes of delivery. The average marks obtained by students in the distance learning programme are 61 (group 1), 74 (group 2) and 72 (group 3). This gives an average mark over these groups of 69 . This is significantly higher numerically than the average mark of 61 for the classroom-based students. But it is not significantly higher in terms of grade. Both of these marks lie within the B+ grade in the University of Paisley grading scheme; in fact, they are the lower and upper boundaries of that grade. We can say that students studying this module by distance learning obtain marks that are significantly higher than the marks obtained by students studying the module by attendance on campus, but that the difference does not extend as far as a difference in grade.

Variations in teacher input due to variations in class numbers

The last factor we consider in our discussion is the input of teachers to these groups, particularly in the light of the different sizes of the groups the teachers are working with. On campus, the average class size in the B.Sc. Health Studies programme is twenty students. The mean score these students are achieving in their assignments for this module is 61 per cent (see Table 1). In the Hong Kong distance-learning mode, the average number of students per tutor group is 20 students. When we aggregate the marks gained by all the students studying by distance learning in Hong Kong (that is, both Chinese and British students), we see that these students are achieving a mean score of 68 per cent in their assignments. The average class size for the United Kingdom-based distance-learning students in this study is nine students. The mean score these students are achieving in their assignments is 72 per cent. These results would at least indicate that the increased contact that students have with their teacher - due to both the means of delivery of their course and their class numbers - leads to increased scores in assignments.

\section{Conclusions}

Both our distance-learning and our classroom-based modes of delivery are enabling students to complete the module 'Professional Practice and Teaching' successfully.

When we compare the average marks obtained by those undertaking the degree by distance learning and those undertaking it on campus, we find that the distance-learning students are obtaining significantly higher marks than the classroom-based students. That difference, though numerically of statistical significance, does not stretch to a grade difference. On average, then, our distance-learning students and our classroom-based students in this module are obtaining the same overall grades.

The term 'distance learning' is no more a unitary term than the term 'classroom-based learning'. In both these modes of delivery there are widely different practices. In the module we have considered here, distance learning encompasses independent learning enhanced by face-to-face tutorials and computer-mediated distance learning with no faceto-face tutorials. We have tried to identify these differences using the average scores 
achieved and the results indicate that the entirely online form of computer-mediated distance learning is associated with the highest scores in the module under consideration.

This is the first stage of our research. It has been a retrospective study. The next step is a prospective study. This forthcoming study will focus on only two modes of delivery, classroom-based study and supported distance learning with no face-to-face contact. Once again the independent variable will be the common assessment, which all students in the study will undertake. However, the role of culture, existing professional background and motivation in the lives of the students who are undertaking this degree programme will continue to influence our findings.

\section{Acknowledgement}

The help of Mr David McVey, writer of distance-learning material, in preparing this manuscript is acknowledged by the authors.

\section{References}

Edwards, N., Hugo, K., Cragg, B. and Peterson, J. (1999), 'The integration of problembased learning strategies in distance education', Nurse Educator, 24 (1), 36-41.

Fung, Y. and Carr, R. (2000), 'Face-to-face tutorials in a distance learning system: meeting student needs', Open Learning, 15 (1), 35-46.

Garrick, R. (1997), 'The National Committee of Inquiry into Higher Education: Report of the Scottish Committee, Chapter 2, section 2.4'. Available from: http:/lwww.leeds. ac.uk/ncihel

Higher Education Statistics Agency. (2000), Higher Education Statistics for the United Kingdom, 1998199, Cheltenham: HESA, Table 1, 8.

Ip, W. Y., Lee, D., Lee, I., Chau, J., Wootton, Y. and Chang, A. (2000), 'Disposition towards critical thinking: a study of Chinese undergraduate nursing students', Journal of Advanced Nursing, 32 (1), 84-90.

Li Yixian (1992) 'On the characteristics, strong points and shortcomings of education in Hong Kong: a mainland Chinese educator's view of education in Hong Kong', in G. A. Postiglione (ed.), Education and Society in Hong Kong: Toward One Country and Two Systems, Hong Kong: Hong Kong University Press.

McGreal, R. (2002), 'Significant difference'. Available from: New Brunswick: TeleEducation, http://teleeducation.nb.ca/significantdifferencelindex.cfm

$\mathrm{Ng}$, K-C. (2001), 'Using e-mail to foster collaboration in distance learning', Open Learning, 16 (2), 191-200.

Peterson, P. W. (2001), 'The debate about online learning: key issues for writing teachers', Computers and Composition, 18, 357-70.

Phipps, R. and Merisotis, J. (1999), What's the Difference? A Review of Contemporary 
Tim Duffy et ol Comparing distance education and conventional education

Research on the Effectiveness of Distance Learning in Higher Education, Washington, Institute for Higher Education Policy. Available from: http://www.ihep.org/Pubs/PDF/Difference.pdf

Russell, T. (1999), The No Significant Difference Phenomenon, Chapel Hill, NC: Office of Instructional Telecommunications, North Carolina State University.

Russell, T. ' (2002), 'The "No Significant Difference" phenomenon'. Available from: http:/lteleeducation.nb.calnosignificantdifferencelindex.cfm

Sumner, J. (2000), 'Serving the system: a critical history of distance education', Open Learning, 15 (3), 267-85.

University Grants Committee (1996), 'Higher education in Hong Kong; a report'. Available from: http://www.ugcedu.hk/hervw/chaptel6.html 